\title{
Research brief: a multi-national survey of critical care nursing certification
}

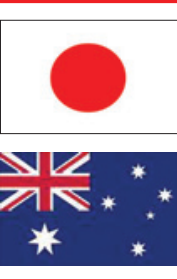

Yuko Ikematsu RN; PhD, Professor, Acute Care Nursing, Department of Nursing, School of Health Sciences, Nagoya University, Japan

Ged Williams RN, RM; CritCareCert, GradCertPSM, BAppSc (Adv. Nursing), GradCertLaw, LLM (QUT), MHA (UNSW), Executive Director of Nursing \& Midwifery, Gold Coast Health Service District, Queensland, Australia; Professor of Nursing, Griffith University, Queensland, Australia; President, World Federation of Critical Care Nurses

E-mail: ikematsu@met.nagoya-u.ac.jp

Key Words: certification critical care nursing * multi-national

\section{SUMMARY}

- This paper presents the findings of a multi-national survey of critical care nursing certification that was conducted in 2007. Representatives from member countries of the World Federation of Critical Care Nurses were surveyed.

- Responses were received from representatives in sixteen countries. Eleven countries provided a critical care nursing certification system at national level, which recognised nurses for their advanced competence in care of the critically ill patient. Although many countries provided more than one type of certification, the criteria were inconsistent. Nurses were certified by a nurses' association, a government body, a university, or a combination of these.

- The survey found that most of the respondents of the countries surveyed valued the certification system and that critical care certification was well recognised by nurses but was less well recognised by physicians and patients.

- It is concluded that standardisation of critical care nursing elements of certification programs may aid their development or refinement. This could be advantageous internationally because globally accepted principles of certification will help to enable nurses who have completed a critical care nursing program in one country to transfer their practice to another country more easily.

\section{INTRODUCTION}

Critical care is one of the newly developed medical specialties and critically ill patients now survive longer due to technological advances. In this context, nurses who care for critically ill patients require specialist knowledge about the patient's physiological, psychological, and spiritual responses to critical illness as well as skills to manage sophisticated technology and equipment.

Certification is seen as one of the ways to assure that an appropriate level of education and knowledge is available to ensure that high quality care is provided to all critically ill patients. Certification may be structured slightly differently in each country and setting. Certification is a process by which a government or non-government agency validates, based upon predetermined standards, an individual nurse's qualification and knowledge for practice in a defined functional or clinical area of nursing. The predetermined standards for critical care nursing certification generally considers the following elements: formal qualifications, the period of time they have worked in the field, continuing knowledge of current practices in critical care nursing, participation in continuing education and clinical experience requirements. The certification generally lasts a finite period after which a renewal, or re-certification process is required (American Association of Critical-Care Nurses, 2008).

The American Association of Critical-Care Nurses began certifying critical care nurses in the USA in 1975 (American Association of Critical-Care Nurses \& American Association of Critical-Care Nurses Certification Corporation, 2003). Other countries and territories may have their own systems to certify critical care nurses, but the literature on the current status of certification in each country is limited. Examining the variety of countries' certification systems may be beneficial to develop or to revise the certification system in each country. This article reports on a multinational survey of critical care nursing leaders regarding their opinions of critical care nursing certification.

\section{METHODS}

A questionnaire was developed by the authors to examine the views of nursing leaders regarding certification in critical care nursing. With respect to each country, the questionnaire included questions about whether or not there was a critical care certification system in place, the certification process, the certifying party, renewal requirements, recognition and standing of the certification, and the respondent's opinion of the certification. The questionnaire was distributed to World Federation of Critical Care Nurses (WFCCN) representatives of member countries on August 27, 2007 via e-mail. Use of the list was approved at a WFCCN meeting during 4th WFCCN Congress, which was held in Sun City, South Africa, August 2007. The authors represented their own countries (Japan and Australia).

In the survey, 'certification' was defined as, a title given to a nurse who receives formal recognition for their advanced competence in taking care of critically ill patients. 'Formally' means that the recognition is beyond a single institution/hospital and must be at least regional level. These definitions were provided to respondents in the cover letter attached to the survey. Although the expression 'certification' can be applied to academic specialisation or professional recognition, this definition limits its scope for clinical practice. 


\section{RESULTS}

The survey was distributed to WFCCN representatives in 32 countries. Sixteen representatives responded, achieving a $50 \%$ response rate. Although the survey questions were not limited to certification at national level, all respondents interpreted it to mean national certification. Therefore, the results and discussion of this article focus on national levels of certification of critical care nursing practice. Eleven countries were noted to have a certification system (see table 1). Five countries (Argentina, Australia, Colombia, Slovenia, and UK) replied that they had no certification on critical care nursing, of which two countries (Colombia and Slovenia) were in the process of developing a certification program and two countries (Australia and UK) had a certification process in the past. The current status of certification in the responding countries is listed in table 1.

Six countries had more than one certification process related to critical care and certification titles other than critical care included paediatric critical care (Canada and USA), progressive care (USA), cardiac medicine and surgery (USA), and anaesthesia (Denmark) and several countries had more than one level of certification in critical care. Examples of these levels are: Certified Critical Care Nurse (CCRN), Critical Care Nurse Specialist (CCNS) and Acute Care Nurse Practitioner (ACNP) in the USA, and Certified Nurse $(\mathrm{CN})$ and Certified Nurse Specialist (CNS) in Japan.

The number of certified critical care nurses varied from two in Iceland (who were educated in the USA) to 50,000 in the USA. The small number of Icelandic certified nurses relates to a 2003 law that now requires master's level education. Before the law changed, there were about 30 certified nurses educated at diploma level.

Nurses were certified by a professional nurses' association in five countries, by the government in three countries, by a university in one country, or by a combination of bodies (government and association; government and university) in two countries. Most of the countries required one or more of the following to be certified: clinical experience, academic or continuing education, and examination.

The respondents' perceptions of the levels of recognition of critical care nursing certification in their countries are shown in table 2. The majority of respondents rated certification as being very well recognised by critical care nurses, but less so by general nurses. It was recognised even less by physicians and least of all by patients and consumers.

Certified nurses or their employers received increased remuneration in five countries. In Scandinavian countries (Denmark and Sweden), certification was mandated in order to work in the intensive care unit. Nine respondents, including those from countries that did not have certification, valued certification as being very necessary. Their reasons included:

- the complexity of critically ill patients,

- the need to guarantee/advance the quality of care,

- an important motivator for nurses,

- integration of theory and practice.

\section{DISCUSSION}

Certification in critical care nursing was widely utilised among the countries studied, which were from all over the world. Although two countries had stopped providing certification, academic preparation of critical care nurses had been in place in these countries, indicating that some recognition of specialisation in critical care nursing remains.

In some countries, such as Japan, nursing has been considered a single specialty, which led to the creation of single nursing divisions in hospitals. Before that, nurses had belonged to medical specialty departments managed by physicians such as orthopaedics, ophthalmology, or cardiology. Uniting all nurses into a single organisational structure enabled them to become more professionally independent. At the same time, this movement made all nurses more equal professionally, and they were expected to work in any clinical area, as needed. Preparation to be generalists was preferred to specialisation. However, recent technological and medical advancement as well as consumers' awareness of medical safety may have the effect of accelerating specialisation in nursing. As the need for specialisation grew, certification became a means by which nurses could demonstrate that they were specialists.

More than half of the countries in this survey had two or more certification processes in critical care, and two countries (Japan and USA) set different levels of critical care certification, that is, basic level and advanced level. Different specialisations of critical care certification were also identified, such as paediatric critical care (Canada) and anaesthesia (Denmark). The USA also provided cardiac medicine and cardiac surgery as sub-specialties. However, these sub-specialisation inclusions were not consistent among the countries studied. For example, CCRN in the USA connotes adult, paediatric or neonatal critical care, but all hold a single title, that is, CCRN. Although cited in the literature (Welk, 2002), inclusion of anaesthesia in critical care in Denmark is unique; the nurse anaesthetist is considered to be a different specialist in many other countries.

These findings suggest that there is no global consensus about what constitutes 'critical care nursing' at this time. Even when limiting the discussion to European countries, there is no universally agreed definition of critical care (Baktoft et al., 2002). WFCCN (2005) developed a definition of critical care nursing that states, "Critical care nursing means assisting, supporting, and restoring the patient towards health, or to ease the patient's pain and to prepare them for a dignified death." However, this statement is very broad and could be applied to nursing in any context. Further discussion and clarification of such definitions may be useful. For example, further clarification of the phrases 'assisting' and/or 'supporting' the critically ill patient and their family would be helpful, as well as discussion about what is understood as 'health' of critically ill patients. These are some of the questions that, if addressed, may help the global community to reach agreement on the boundaries of critical care nursing and may therefore help to better define the scope of critical care nursing certification.

The authority for certifying critical care nurses was a nurses' association in five countries. Of these, the professional association was for all nurses in three countries (Canada, Japan, Nigeria), for critical care nurses only in one country (USA), and both associations in one country (Taiwan). In Taiwan, the Taiwan Nurses Association and the Taiwan Association of Critical Care Nurses offered independent certification. Each association had different requirements for clinical experience although they shared the same examination. In the USA, critical care nurses are certified by the American Association of Critical-Care Nurses, which was one of the leading nursing associations that initiated specialisation in nursing in the USA (Keeling \& Bigbee, 2005).

Certification by a general nursing association may be a useful means to standardise the requirement and reputation across all specialty areas while certification by a critical care association may provide specialty-focused standards that are important and unique to the specialty. Certification by a specialty organisation, which is already highly regarded in the case of the American Association of CriticalCare Nurses, may facilitate strong recognition of certified nurses. However, in countries where the critical care nurses association is underdeveloped, certification by a general nurses association may 
be seen as more effective in promoting community and professional awareness of the unique and important role of critical care nursing.

The government is involved in certification in five countries. Influences of government regulation may vary depending on the country's situation. It is not necessarily linked to monetary remuneration currently, but it can be a strong support to acquire social value. For example, Scandinavian countries (Denmark, Sweden) mandate formal education and certification in order to work in intensive care, and the representatives from both countries rated critical care certification as being highly recognised by health care providers as well as by consumers.

Most of the responding countries required the nurse to have undertaken formal specialist education to be certified. In some countries, one of the obstacles to certification may be the lack of, or an inadequate, critical care nursing curriculum. In countries that lack a specialist nursing curriculum, there are multiple approaches that can be used to develop a curriculum. The WFCCN provides guidance on the provision of critical care nursing education via a position statement (WFCCN, 2005), however in some situations a country may base the curriculum on role expectations. For example, in Japan the Japanese Nursing Association (2008) has identified the roles of Certified Nurse (CN) and Certified Nurse Specialist (CNS). The sub-roles for the $\mathrm{CN}$ are:

$\begin{array}{ll}\text { - } & \text { high level of nursing practice } \\ \text { - } & \text { leadership } \\ \text { consultation }\end{array}$

and for the CNS are:

$\begin{array}{ll}\text { - } & \text { excellence in practice } \\ \text { - } & \text { consultation } \\ \text { - } & \text { ethical coordination } \\ \text { - } & \text { education } \\ \text { - } & \text { research activities }\end{array}$

Nurses are expected to demonstrate these roles within their own specialties and each specialty curriculum was developed in accordance with these roles. This approach is effective, and helps consumers to understand the nurse's role. However, role-oriented approaches tend to be limiting in that they focus on current practices. In order to identify competencies that enable expansion of current roles, innovative approaches are needed (Curley, 1996).

In the USA, the American Association of Critical-Care Nurses Certification Corporation developed the Synergy Model as a framework of critical care nurse competency (Curley, 1996). This model is unique because its development is based on patient characteristics. Although it is frequently stated that critical care nurses require specialised skills and knowledge, the rationale for the particular skills and knowledge has not been fully articulated. The Synergy Model may be a useful framework for curriculum as well as examination development.

In developing an educational curriculum, global standards may be warranted in addition to local needs. For example, Taiwan utilises the Advanced Cardiac Life Support (ACLS) license as an adjunct requirement for critical care nursing certification. ACLS and other globally recognised standards of practice may be helpful to ensure a universal level of competency for certification.

Critical care certification is well recognised by critical care nurses in many of the countries surveyed, but less recognised by general nurses, patients, and physicians. It is important to promote recognition by a variety of stakeholders, as this has reciprocal influences such as increased motivation of critical care nurses, increased numbers of certified nurses, increased patient satisfaction, and improved quality of care and patient outcomes.

It is suggested that the primary purpose of certification is to improve the quality of patient care and it is contended that to achieve this goal research evidence is needed that examines differences between certified and uncertified nurses in terms of their quality of care, patient outcomes, and patient satisfaction.

All but one of the respondents rated certification as 'very necessary' or 'necessary'. The Philippine respondent rated 'not very necessary', because they have the more serious and urgent problem of emigration of nurses. In the Philippines, experienced nurses tend to seek jobs in foreign countries where they are offered higher salaries. (Rogado, 2006) The Philippines has established excellent basic nursing programs, and the nurses are well prepared to work in a variety of countries. It is an irony that good education facilitates nurse emigration, resulting in a nursing expertise shortage. This phenomenon indicates that nursing specialisation is affected by political or economical stability. Such influences are also found in Argentina where a certification system does not exist. The Argentine respondent attributed the absence of certification to:

- lack of higher education in nursing

- social and economic conditions of nurses

- weakness of the nursing organisation

- lack of leadership

- the constitution of the nursing workforce that permits auxiliary nurses

Also, it was noted that the development of a certification system was not a priority while other more fundamental needs existed within the profession. Although certification is an important issue, which nurse leaders should draw attention to, other issues may override its priority depending upon each country's situation.

The reasons found in this study, for the necessity of certification, varied from guaranteeing the level of care to advancing the excellence of care. In Japan, CNs are expected to ensure standards of the care of their units whereas the CNS is expected to advance expert or 'cutting edge' care. Thus, there are two levels of certification. Because of increasing diversity of patient needs as well as nurses' backgrounds and the complexity of information/medical technology, single certified nurse may not be able to perform all roles expected of the advanced critical care nurse.

In the USA, the American Association of Critical-Care Nurses has developed a new certification program in addition to the CCRN. The newer credentials are Progressive Care Certified Nurse (PCCN), Critical Care Nurse Specialist (CCNS), Acute Care Nurse Practitioner (ACNP), Cardiac Medicine Certification (CMC) and Cardiac Surgery Certification (CSC) as subspecialties. Collaboration of nurses with different certifications and expertise may help to promote comprehensive meeting of patient care needs, which may lead to improved patient outcomes.

Two countries (Australia and UK) have discontinued certification. In the UK, diploma or graduate status is higher than certificate, so that the certificate was stopped in 2002. In Australia, the Australian College of Critical Care Nurses developed a critical care certification program in 1999, but there were only about twenty applicants during the first five years, and the number of the applicants then declined to close to zero. The Australian respondent suggested the following possible reasons for this:

- the cost for the certification does not meet the benefit (including monetary remuneration) associated with the certification 
- the effort of advertisement diminished rapidly in response to the poor response

- certification is not popular in Australian nursing

- certification may not match Australian nursing culture at this time

Although certification no longer exists in these countries, post graduate nursing diploma and/or degree programs are provided, and it is these that endorse nurses' competence to practice in specialty areas. While Australia and UK do not have certification processes, it is clear that formal educational preparation is considered to be highly desirable for critical care nursing.

In Japan, although there are many new graduate nursing programs, their focus is not always clinically oriented, especially at large universities. In addition, there is a shortage of clinically well-prepared educators, which results in inconsistent educational outcomes. Therefore, certification examination is required for clinical nurse specialists in addition to a master's degree. As graduate programs mature and establish consistent standards in terms of curriculum, faculty, and resources, a separate certification process may not be required in the future.

\section{Limitations}

The findings of this study are limited because there were only sixteen responding countries, and they are all WFCCN member countries. Other countries may have different perceptions of critical care nursing and requirements for its certification. Furthermore, this study concentrated on certification in isolation from other aspects of critical care nursing such as the minimum requirement to be a critical care nurse, the scope of critical care nursing practice, and critical care nursing content in the basic nursing curriculum.

\section{CONCLUSIONS}

Further exploration of certification as well as practice and education of critical care nursing worldwide is needed. Information obtained through surveys such as this may identify universal characteristics of critical care nursing and nurses that may inform certification requirements. Such characteristics could provide core material for a certification program, and may help inform a global standard of critical care nursing education. Countries developing certification or other programs would then be able to utilise global standards of education that could be modified to fulfill their local needs.

Certification of some kind, resulting in formal recognition may be essential to support improved quality of critical care nursing and common agreement about the required elements in certification programs may aid their development and refinement. Globally accepted principles may enable nurses who completed the program in one country to interact internationally; communication and sharing of certification processes across international borders would be valuable to promote advancement of critical care nursing worldwide.

\section{ACKNOWLEDGEMENTS}

The authors wish to thank the following people for their participation in this study: Laura Alberto (Argentina), Lourdes Zeballos (Bolivia), Bernice Budz (Canada), Myriam Parra (Colombia), Birte Baktoft (Denmark), Lovísa Baldursdóttir (Iceland), Adamu Majidadi (Nigeria), Rossana Gonzales (Peru), Ma. Isabelita Rogado (Philippines), Drago Satosek (Slovenia), Eva Barkestad (Sweden), Yolanda Huang (Taiwan), John Albarran (UK), and Justine Medina (USA). The authors wish to convey special thanks to Laura Alberto for translating the survey into Spanish.

A part of this study was presented at the 37 th Critical Care Congress, Honolulu, in February 2008.

\section{REFERENCES}

American Association of Critical-Care Nurses and AACN Certification Corporation (2003). Safeguarding the patient and the profession: The value of critical care nurse certification. American Journal of Critical Care 12 (2), 154-164.

American Association of Critical-Care Nurses (2008). General information regarding certification. [Online]. Available at: http:// www.aacn.org/WD/Certifications/Content/generalinfo.pcms?menu $=$ Certification\&lastmenu= [Accessed 20 December, 2008].

Baktoft B, Drigo E, Hohl ML, Klancar S, Tseroni M, Putzai P (2002). A survey of critical care nursing education in Europe. Connect: The World of Critical care Nursing 2 (3), 85-87.

Curley MAQ (1996). The Synergy Model of certified practice: Creating safe passage for patients (Interview). Critical Care Nurse 16 (4), 95-99.

Japanese Nursing Association (2008). Development of human resources with advanced specialization [Online]. Available at: http://www.nurse.or.jp/jna/english/nursing/development. html\#specialist [Accessed 9 August, 2008].

Keeling AW, Bigbee JL (2005). The history of advanced practice nursing in the United States, In: Hamric AB, Spross JA, Hanson CM, (eds.), Advanced Practice Nursing: An Integrative Approach (3rd ed.). St. Louis: Elsevier Saunders.

Rogado MIC (2006). Nursing in the Philippines. Journal of the Japanese Society of Intensive Care Medicine 13, 229-233.

Welk I (2002). Scopes and aims in anaesthesia and critical care nursing. Connect: Critical Care Nursing in Europe 2(2), 53-54.

WFCCN (2005). WFCCN Activity Report from 2001 to 2005 [On line]. Available at: http://www.wfccn.org/webdocs/wfccn_report. pdf [Accessed 9 August, 2008]

WFCCN (2005). WFCCN Position Statement on the Provision of Critical Care Nursing Education - Declaration of Madrid, 2005. Available at: http://en.wfccn.org/pub_education.php [Accessed 9 August, 2008]. 